\title{
MOTIVASI WANITA PASANGAN USIA SUBUR DALAM PEMERIKSAAN IVA DI DESA CANGKORAH BATUJAJAR
}

\author{
Fathia Rizki, Suci Nur Hasanah
}

\begin{abstract}
ABSTRAK
Latar Belakang: Penyakit kanker merupakan penyebab kematian terbanyak di dunia. Setiap tahun 12 juta orang di dunia menderita kanker dan 7,6 juta diantaranya meninggal dunia. Dalam upaya penanggulangan kanker pemerintah melaksanakan program khusus deteksi dini pada perempuan Indonesia untuk kanker leher rahim yaitu pemeriksaan IVA. Cakupan pemeriksaan IVA di Indonesia tahun 2016 yaitu 4,34\% hal ini masih jauh dari target nasional yaitu $10 \%$.

Tujuan Penelitian: Untuk mengetahui hubungan motivasi dengan keikutsertaan melakukan deteksi dini kanker serviks metode IVA Tes di Wilayah Kerja Puskesmas Batujajar Desa Cangkorah Tahun 2018.

Metode Penelitian: Penelitian ini menggunakan metode penelitian analitik dengan desain Cross sectional. Sampel pada penelitian ini adalah wanita pasangan usia subur yang berada di desa Cangkorah sebanyak 285 orang dengan teknik stratified random sampling, di analisis secara bivariat menggunakan Chi Square.

Hasil: Lebih dari setengah $(59,6 \%)$ atau 170 orang memiliki motivasi yang rendah dalam pemeriksaan IVA Tes dan hanya sebagian kecil $(9,1 \%)$ atau 26 orang yang pernah melakukan pemeriksaan IVA Tes.

Simpulan: Terdapat hubungan antara motivasi wanita pasangan usia subur dan keikutsertaan melakukan deteksi dini kanker serviks metode IVA tes di wilayah kerja Puskesmas Batujajar Desa Cangkorah Tahun 2018.
\end{abstract}

Kata Kunci: IVA Tes; keikutsertaan; motivasi.

\section{PENDAHULUAN}

Menurut data WHO (World Health Organization) tahun 2013 insiden kanker meningkat dari 12,7 juta kasus pada tahun 2008 menjadi 14,1 juta kasus tahun 2012 sedangkan jumlah kematian meningkat dari 7,6 juta orang pada tahun 2008 menjadi 8,2 juta orang pada tahun 2012 (Kementrian kesehatan RI, 2014). Penyakit kanker serviks merupakan penyakit kanker dengan prevalensi tertinggi di Indonesia pada tahun 2013, yaitu kanker serviks sebesar 0,8\%. Provinsi Kepulauan Riau, Provinsi Maluku Utara, dan Provinsi D.I. Yogyakarta memiliki prevalensi kanker serviks tertinggi, yaitu sebesar 1,5\%. Berdasarkan estimasi jumlah penderita kanker serviks dan kanker payudara terbanyak terdapat pada Provinsi Jawa Timur dan Provinsi Jawa Tengah (Kemenkes RI, 2015).

Kanker adalah pertumbuhan sel yang tidak normal/terus menerus dan tak terkendali, dapat merusak jaringan sekitarnya serta dapat menjalar ke tempat yang jauh dari asalnya yang disebut 
metastasis (Dinas Kesehatan RI, 2009). Tingginya prevalensi kanker di Indonesia perlu dicermati dengan tindakan pencegahan dan deteksi dini yang telah dilakukan oleh penyedia layanan kesehatan (Kemenkes RI, 2015).

Tingginya jumlah penderita kanker serviks di Indonesia idealnya diimbangi dengan tingginya jumlah provider (pelaksana program, yang terdiri dari dokter umum dan bidan) dan skrining di Puskesmas. Sampai dengan tahun 2013, terdapat 1.682 providerdeteksi dini kanker serviks dan kanker payudara di Indonesia dengan estimasi jumlah kanker serviks sebanyak98.692 kasus dan kanker payudara sebanyak 61.682 kasus (Kemenkes RI, 2015).

Prevalensi dan estimasi jumlah Penderita Penyakit Kanker Serviks di Jawa Barat berada pada kisaran angka 0,7\% atau sebanyak 15.635. Dengan demikian Jawa Barat menjadi provinsi ketiga terbanyak setelah provinsi Jawa Timur yaitu 1,2\% atau sebanyak 21.313, lalu pada urutan kedua yaitu provinsi Jawa Tengah yaitu 1,1\% atau sebanyak 19.734 (Riset Kesehatan Dasar, 2013).

Angka kejadian kanker serviks di Kabupaten Bandung Barat selama periode bulan Juli hingga Desember 2017 mencapai 14 orang yang rata-rata rentang usia 30-59 tahun dengan jumlah yang melakukan pemeriksaan 6.683 orang (Dinas Kesehatan Kabupaten Bandung Barat, 2017).

Beberapa faktor risiko yang menyebabkan seorang wanita terkena kanker serviks, yaitu melakukan hubungan seksual sebelum usia 20 tahun, berganti-ganti pasangan seksual, paritas tinggi, penggunaan kontrasepsi oral jangka panjang, merokok, riwayat kanker serviks pada keluarga, usia, defisiensi nurtrisi, perawatan organ reproduksi yang salah, lemahnya imunitas, infeksi klamidia, kelebihan berat badan dan kemiskinan (Savitri, 2015).

Menurut Sub Direktorat Kanker Penyakit Tidak Menular, Direktorat Jenderal Pengendalian Penyakit dan Penyehatan Lingkungan Kementerian Kesehatan RI sampai dengan tahun 2013, program deteksi dini kanker serviks dan kanker payudara baru diselenggarakan pada 717 Puskesmas dari total 9.422 Puskesmas di 32 provinsi. Dengan demikian, dapat dilihat bahwa Puskesmas yang memiliki program deteksi dini masih sangat sedikit atau sekitar 7,6\%(Kemenkes RI, 2015).

Sejak tahun 2007-2016 sudah dilakukan 5,15\% pemeriksaan IVA pada perempuan di Indonesia. Cakupan pemeriksaan IVA tertinggi terdapat di Bali, yaitu sebesar 19,57\%, diikuti oleh DKI Jakarta sebesar 12,09\%, dan Nusa Tenggara Barat sebesar 11,42\%, dan untuk Jawa Barat hanya mendapat angka sebesar 3,49\% (Profil Kesehatan Indonesia, 2016). 
Cakupan deteksi dini kanker seviks melalui pemeriksaan IVA di Jawa Barat, yaitu sebesar 3\% angka tersebut masih jauh dari cakupan target nasional sebesar 10\% (Kementrian Kesehatan, 2016). Cakupan deteksi dini kanker serviks di Kabupaten Bandung Barat memiliki wanita usia subur usia 20-29 tahun sebanyak 31.323 orang dengan jumlah pemeriksaan IVA sebanyak 3.885 orang, sedangkan untuk wanita usia subur usia 30-59 tahun sebanyak 157.213 orang dengan jumlah pemeriksaan IVA sebanyak 1.399 orang. (Dinkes KBB, 2017). Cakupan deteksi dini kanker serviks menurut Dinkes KBB (2017), didapatkan cakupan tertinggi di puskesmas Batujajar dengan jumlah pemeriksaan sebanyak 261 wanita usia subur sedangkan untuk cakupan terendah di puskesmas Gununghalu sebanyak 8 wanita usia subur (Dinkes KBB, 2017).

Puskesmas Batujajar merupakan puskesmas yang membawahi 6 desa, yaitu Batujajar Barat, Batujajar Timur, Galanggang, Pangauban, cangkorah dan Selacau. Berdasarkan hasil studi pendahuluan diperoleh hasil bahwa jumlah wanita pasangan usia subur di wilayah kerja puskesmas Batujajar sebanyak 20.186 wanita usia subur dengan hasil pemeriksaan IVA tahun 2017 sebanyak 594 wanita pasangan usia subur. Sampai saat ini angka kejadian kanker serviks di Kecamatan Batujajar tidak ada. Cakupan deteksi dini kanker serviks tertinggi berada di desa Batujajar barat dengan hasil pemeriksaan deteksi dini kanker serviks sebanyak 149 orang, desa Galanggang 139 orang, desa Batujajar Timur 126 orang, desa pangauban 66 orang, desa Selacau 58 orang,dan yang terendah yaitu desa Cangkorah 36 orang.

Berdasar atas hasil studi pendahuluan Desa Cangkorah terletak di Kecamatan batujajar Kabupaten Bandung barat yang memiliki luas wilayah yaitu sebesar 344 Ha dengan jumlah penduduk 10.792 jiwa, 3350 kepala keluarga yang terdiri dari $17 \mathrm{RW}$ terhitung dari bulan Juli 2017. Untuk wanita pasangan usia subur yang berada di desa Cangkorah yaitu sebanyak 1.177 orang, darri jumlah tersebut yang melakukan pemeriksaan IVA tes di puskesmas Batujajar yaitu hanya 36 orang.

Berdasar atas data dan latar belakang masalah di atas maka penulis tertarik untuk melakukan penelitian dengan judul hubungan motivasi wanita pasangan usia subur dengan keikutsertaan melakukan deteksi dini kanker serviks metode Inspeksi Visual Asam Asetat (IVA) Test Wilayah Kerja Puskesmas Batujajar di desa Cangkorah Kab. Bandung Barat Tahun 2018.

\section{METODE}


Penelitian ini menggunakan metode penelitian analitik dengan desain Cross sectional.Variabel yang diteliti pada penelitian ini terdiri dari dua yaitu motivasi wanita pasangan usia subur dan keikutsertaan melakukan deteksi dini kanker serviksIVA tes. Untuk menghitung banyaknya sampel yang akan diteliti, maka peneliti menggunakan rumus Isaac dan Michael. Jumlah sampel dalam penelitian ini adalah 285 orangwanita pasangan usia subur yang berada di lingkungan wilayah kerja puskesmas Batujajar yaitu di desa Cangkorah. Teknik pengambilan sampel yang digunakan dalam penelitian ini yaitu Stratified Random Sampling.

Adapun untuk pengumpulan data menggunakan data primer dan sekunder. Instrument yang digunakan dalam penelitian ini adalah kuesioner dan rekam medik. Sebelum dilakukan penelitian instrument yang digunakan yaitu kuesioner dilakukan uji validitas dan realibiltas terlebih dahulu yaitu di Desa Selacau, dari 20 soal setelah dilakukan uji validitas dan realibilitas maka yang dapat digunakan yaitu 14 soal dan untuk 6 soal yang tidak valid tidak digunakan dalam penelitian.Penelitian ini menggunakan analisis univariat untuk mengetahui distribusi frekuensi dari kedua variabel dan analisis bivariat untuk mengetahui adanya hubungan menggunakan uji statistic Chi-square.

\section{HASIL}

Tabel 4.1 Distribusi Frekuensi Motivasi Wanita Pasangan Usia Subur di Desa Cangkorah Tahun 2018

\begin{tabular}{lll}
\hline Motivasi & Frekuensi & Persentase (\%) \\
\hline Tinggi & 115 & 40.4 \\
Rendah & 170 & 59.6 \\
\hline Total & $\mathbf{2 8 5}$ & $\mathbf{1 0 0}$ \\
\hline
\end{tabular}

Berdasar Tabel 4.1 di atas menunjukkan bahwa dari 285 responden didapatkan bahwa lebih dari setengah wanita pasangan usia subur $(59,6 \%)$ atau 170 responden memiliki motivasi yang rendah dalam pemeriksaan IVA Tes di Desa cangkorah.

Tabel 4.2Distribusi Frekuensi Wanita Pasangan Usia Subur Berdasarkan Keikutsertaan Melakukan Deteksi Dini Kanker Serviks Metode IVA Tes

\begin{tabular}{lll}
\hline Keikutsertaan & Frekuensi & Persentase (\%) \\
\hline Pernah & 26 & 9.1 \\
Tidak Pernah & 259 & 90.9
\end{tabular}




\begin{tabular}{lll}
\hline Total & 285 & 100
\end{tabular}

Berdasar Tabel 4.2 menunjukkan bahwa dari 285 responden hanya sebagian kecil $(9,1 \%)$ atau 26 orang yang pernah melakukan pemeriksaan IVA Tes.

Tabel 4.3 Hubungan Motivasi Wanita Pasangan Usia Subur Dengan Keikutsertaan Melakukan IVA Tes

\begin{tabular}{|c|c|c|c|c|c|c|c|}
\hline & \multicolumn{7}{|c|}{ Keikutsertaan Iva Tes } \\
\hline & \multicolumn{2}{|c|}{ Pernah } & \multicolumn{2}{|c|}{ Tidak Pernah } & \multirow[t]{2}{*}{ Jumlah } & \multirow[t]{2}{*}{$\%$} & \multirow[t]{2}{*}{$P$} \\
\hline & $\mathbf{F}$ & $\mathbf{P}$ & $\mathbf{F}$ & $\mathbf{P}$ & & & \\
\hline Tinggi & 26 & 22,6 & 89 & 77,4 & 115 & 100 & \\
\hline Rendah & 0 & 0 & 170 & 100 & 170 & 100 & \\
\hline Total & 26 & 9,1 & 259 & 90,9 & 285 & 100 & \\
\hline
\end{tabular}

Berdasar Tabel 4.3 menunjukan bahwa hanya sebagian kecil $(22,6 \%)$ atau 26 orang wanita pasangan usia subur yang memiliki motivasi tinggi pernah melakukan IVA tes dan tidak ada satupun $(0 \%)$ yang melakukan IVA tes pada wanita pasangan usia sibur yang memiliki motivasi rendah. Adapun wanita yang memiliki motivasi tinggi namun tidak pernah melakukan IVA tes, yaitu 89 orang $(77,4)$. Hasil uji Chi-Square diketahui $P$ value $=0,000$ maka Ho ditolak, artinya terdapat hubungan antara motivasi wanita pasangan usia subur dengan keikutsertaan melakukan deteksi dini kanker serviks metode IVA tes.

\section{PEMBAHASAN}

Berdasar hasil penelitian gambaran motivasi wanita pasangan usia subur di desa Cangkorah Tahun 2018 bahwa dari 285 responden sebagian besar wanita pasangan usia subur memiliki motivasi yang rendah. Salah satu faktor yang dapat mempengaruhi tingkat motivasi seseorang adalah pendidikan. Hasil penelitian menyatakan bahwasebagian besar responden berpendidikan menengah pertama sehingga hal tersebut mempengaruhi pengetahuan dari responden.

Hal ini sejalan dengan teori yang diungkap oleh Ferlian (2011), semakin tinggi pendidikan seseorang menjadikan seseorang akan memiliki pengetahuan yang luas dan pola pikirnya terbangun dengan baik. Pendidikan merupakan salah satu faktor penting yang mendorong seseorang untuk lebih perduli dan termotivasi untuk meningkatkan derajat kesehatan dirinya termasuk dalam hal melakukan pemeriksaan IVA sebagai salah satu metode deteksi dini kanker serviks. 
Menurut Notoatmodjo (2014) pengetahuan merupakan hasil tahu, dan ini terjadi setelah orang melakukan penginderaan terhadap suatu objek tertentu. Penginderaan terjadi melalui panca indera manusia, yakni indera penglihatan, pendengaran, penciuman, rasa dan raba. Sebagian besar pengetahuan manusia diperoleh melalui mata dan telinga. Pengetahuan atau kognitif merupakan domain yang sangat penting untuk terbentuknya perilaku seseorang.

Hal ini didukung oleh penelitian Pasaribu (2013), tentang gambaran pengetahuan ibu usia 25-40 tentang pemeriksaan Inspeksi Visual Asam Asetat berdasar atas pendidikan semakin baik pengetahuan responden tentang pemeriksaan IVA.

Selain itu mayoritas responden wanita pasangan usia subur di desa Cangkorah dari jumlah 285 responden hampir seluruh responden tidak bekerja atau Ibu Rumah Tangga (IRT) dan hanya sebagian kecil responden bekerja sebagai karyawan swasta..

Menurut Theresia, Karningsih dan Delmaifanis (2012), lingkungan pekerjaan memungkinkan WUS mendapatkan informasi mengenai deteksi dini kanker serviks dengan metode pemeriksaan IVA. Selain itu, pekerjaan dikaitkan dengan daya beli sehingga wanita yang bekerja akan semakin mandiri dan semakin mudah untuk memeriksakan kesehatannya.

Melihat dari hasil penelitian, peneliti menyimpulkan bahwa Wanita Pasangan Usia subur yang tidak bekerja memiliki motivasi yang lebih besar untuk melakukan pemeriksaan IVA karena Wanita Pasangan Usia Subur yang tidak bekerja memiliki lebih banyak waktu luang untuk mendapatkan dukungan, tukar pendapat atau pengalaman di lingkungan rumah sehingga akan lebih termotivasi untuk melakukan pemeriksaan IVA dibandingkan dengan Wanita Pasangan Usia Subur yang bekerja karena lebih menghabiskan waktunya di tempat pekerjaannya.

Hal ini sejalan dengan penelitian Kursani (2016), WUS yang tidak bekerja memiliki lebih banyak waktu luang yang dapat dipergunakan untuk melakukan kunjungan IVA, ibu yang tidak bekerja juga memiliki pengetahuan yang cukup yang diperoleh terutama dari kader kesehatan.

Beda halnya dengan tinjauan di lapangan mayoritas wanita pasangan usia subur tidak bekerja serta memiliki motivasi yang rendah hal ini bisa disebabkan karena kurangnya pengetahuan mengenai IVA tes, kekhawatiran akan hasil dari pemeriksaan, kurangnya dukungan keluarga serta rasa malu yang dialami oleh responden ketika harus melakukan pemeriksaan pada organ genital nya. Adapun hasil penelitian gambaran keikutsertaan wanita pasangan usia subur dalam melakukan deteksi dini kanker serviks melalui pemeriksaan IVA di desa Cangkorah Tahun 2018, yaitu dari jumlah responden 285 orang hanya sebagian kecil 
responden atau wanita pasangan usia subur yang pernah melakukan pemeriksaan IVA dan melakukan pemeriksaan IVA di Puskesmas Batujajar.

Berdasar atas penelitian Mayasari (2017) terdapat faktor-faktor yang mempengaruhi wanita usia subur tidak berminat dalam pelaksanaan IVA Tes yaitu pengetahuan, sikap, dukungan suami. Dari hasil penelitian Mayasari (2017), responden yang berpengetahuan baik tentang tes IVA akan mempunyai kepatuhan dalam melakukan tes IVA karena mereka tahu bahaya serta dan dampak dari penyakit yang paling ditakuti wanita yaitu kanker leher rahim. Dengan adanya tes IVA kanker leher rahim dapat ditemukan pada stadium awal. Responden yang menjalani tes IVA cenderung mendapatkan informasi tentang tes IVA lebih banyak dibandingkan dengan responden yang tidak menjalani tes IVA.

Dukungan dari suami lebih cenderung melakukan tes IVA, dikarenakan adanya bentuk dorongan dari orang terdekat, maka seorang ibu tersebut telah mendapatkan stimulasi positif. Adapaun wujud dukungan dari suami dapat ditunjukkan oleh suami melalui kegiatan seharihari, misalnya memberikan informasi kepada ibu mengenai pentingnya pemeriksaan IVA atau mengantarkan ibu untuk melakukan IVA tes.

Salah satu faktor yang berhubungan dengan keikutsertaan wanita pasangan usia subur melakukan IVA tes yaitu adanya media untuk mengakses informasi. Hal ini didukung oleh penelitian dari Kursani (2016), responden yang tidak menggunakan akses informasi berisiko 5 kali untuk berpeluang tidak periksa IVA dibandingkan dengan WUS yang menggunakan akses informasi.

Menurut Notoatmodjo (2012), akses informasi hakekatnya mendukung atau memungkinkan terwujudnya pelaksanaan deteksi dini kanker serviks, faktor ini disebut faktor pendukung. Akses informasi mengenai kesehatan reproduksi terutama kesehata reproduksi wanita dapat diperoleh dari majalah, leaflet, poster, televisi, buku kesehatan dan lainnya.

Dari hasil penelitian, peneliti menyimpulkan bahwa pada wanita pasangan usia subur banyak yang tidak melakukan pemeriksaan IVA dipengaruhi tidak adanya akses informasi yang digunakan untuk mencari informasi mengenai deteksi dini yang dapat dilakukan untuk pencegahan kanker serviks, adapun cara sosialisasi menggunakan akses informasi seperti media elektronik ataupun cetak memang masih kurang di masyarakat sehingga itu menjadi salah satu faktor yang membuat wanita pasangan usia subur enggan mengaksesnya. Akan lebih baik jika program deteksi dini tersebut dapat dibuat iklan di media elektronik seperti televisi, radio dll sehingga akan meningkatkan minat dari wanita pasangan usia subur untuk melakukan 
IVA tes. Namun ada juga masyarakat yang mengganggap jika belum ada keluhan maka tidak akan melakukan pemeriksaan kesehatan contohnya seperti pemeriksaan IVA.

Adapun faktor lain yang mempengaruhi keikutsertaan yaitu karena kurangnya penyuluhan-penyuluhan tentang metode IVA. Setelah dilakukan penelitian tinjauan di lapangan masih banyak responden yang tidak mengetahui apa itu pemeriksaan IVA. Hal ini tentu dapat berakibat pada rendahnya cakupan IVA di Puskesmas Batujajar khususnya desa Cangkorah karena kurangnya informasi mengenai program deteksi dini kanker serviks yang dikelola oleh Puskesmas.

Hal ini sejalan dengan penelitian Kursani (2016) kurangnya penyuluhan dari tenaga kesehatan dapat dipengaruhi oleh kurangnya tenaga penyuluh dan kurangnya wakttu luang, sehingga penyuluhan pun hanya dapat dilakukan di puskesmas dengan keterbatasan peserta yang hadir, sehingga kunjungan IVA masih belum merata oleh WUS, dalam hal ini penyuluhan oleh tenaga kesehatan sangat membantu wanita untuk meningkatkan pengetahuan, kesadaran, kemauan dan kemampuan WUS dalam ikut serta metode IVA, akan tetapi jika petugas kesehatan tidak melakukan pendekatan dan penyuluhan terkait metode IVA maka kunjungan IVA pun akan sedikit. Hal ini karna petugas kesehatan merupakan orang yang dipercaya oleh masyarakat terutama WUS, dimana petugas kesehatan memiliki keahlian selain pengobatan juga dalam penyampaian informasi yang benar, sehingga jika adanaya penyuluhan maka akan mendorong wanita untuk melakukan pemeriksaan IVA.

Menurut hasil penelitian salah satu faktor yang mempengaruhi keikutsertaan wanita pasangan usia subur ialah jarak antara rumah dengan fasilitas kesehatan (Puskesmas) yang cukup jauh sehingga membuat masyarakat merasa enggan untuk melakukan pemeriksaan IVA.

Berdasarkan hasil penelitian hubungan antara motivasi wanita pasangan usia subur dengan keikutsertaan melakukan deteksi dini kanker serviks metode IVA tes di wilayah kerja puskesmas Batujajar desa Cangkorah tahun 2018 didapatkan hasil bahwa sebagian besar wanita pasangan usia subur mempunyai motivasi rendah yaitu (59,6\%). Hasil uji Chi-Square menunjukan p-value 0,000 artinya hipotesis nol ditolak maka terdapathubungan yang bermakna antara motivasi wanita pasangan usia subur dengan keikutsertaan melakukan deteksi dini kanker serviks metode IVA tes.

Rendahnya motivasi wanita pasangan usia subur ini berdapampak terhadap cakupan pemeriksaan IVA di Puskesmas Batujajar. Hal ini didukung oleh penelitian dari (Sari, 2017) bahwa mayoritas motivasi wanita pasangan usia subur untuk melakukan deteksi dini kanker serviks adalah rendah (60\%). Deteksi dini kanker ialah usaha untuk mengidentifikasi atau 
mengenali penyakit atau kelainan yang secara klinis belum jelas, dengan menggunakan tes (uji), pemeriksaan atau prosedur tertentu yang dapat digunakan secara tepat untuk membedakan orang-orang yang kelihatannya sehat, benar-benar sehat, dan yang tampak sehat tetapi sesungguhnya menderita kelainan (Rasjidi, 2008).

Motivasi untuk melakukan pemeriksaan IVA, dapat muncul dalam diri seseorang akibat adanya keinginan terbebas dari masalah dan adanya interaksi dengan orang lain dan lingkungan sekitar. Hal ini sesuai dengan teori motivasi menurut Mc Clelland (Notoatmodjo, 2009), bahwa motif primer secara alamiah akan timbul pada setiap individu, sedangkan motif sekunder merupakan motif yang timbul pada diri individu akibat interaksi dengan orang lain.

Adapun faktor-faktor yang mempengaruhi motivasi yaitu faktor fisik dan mental, faktor hereditas, lingkungan, kematangan usia, faktor intrinsik seseorang (pengetahuan, pendidikan dan pekerjaan), fasilitas (sarana dan prasarana), sosial budaya dan media yang digunakan. Faktor lingkungan mempengaruhi motivasi karena semua kondisi yang berasal dari internal dan eksternal yang mempengaruhi dan berakibat terhadap perkembangan dan perilaku seseorang dan kelompok.

\section{SIMPULAN}

Berdasar hasil penelitian dapat disimpulkan bahwa sebagian besar wanita pasangan usia subur di Desa Cangkorah Tahun 2018 memiliki motivasi yang rendah, hampir seluruh wanita pasangan usia subur di Desa Cangkorah Tahun 2018 tidak pernah melakukan pemeriksaan IVA tes, dan terdapat hubungan antara motivasi wanita pasangan usia subur dengan keikutsertaan melakukan deteksi dini kanker serviks metode IVA tes.

\section{SARAN}

Disarankan kepada wanita pasangan usia subur dan masyarakat untuk meningkatkan wawasan dalam pemeriksaan kesehatan khususnya dalam pemeriksaan IVA. Kepada tempat penelitian serta Dinas Kesehatan agar lebih mensosialisasikan program deteksi dini kanker serviks dan meningkatkan Komunikasi Informasi dan Edukasi (KIE) tentang skrining kanker serviks metode IVA. Kepada peneliti selanjutnya dapat melakukan penelitian lebih lanjut dengan metode yang berbeda seperti metode kualitatif.

\section{DAFTAR PUSTAKA}


Arikunto S. 2013. Prosedur penelitian suatu pendekatan praktik. Jakarta: Rineka Cipta.

Aziz F, Andrijono, Abdul BS. 2010. Buku Acuan Nasional Onkologi Ginekologi. Jakarta: Bina Pustaka Sarwono Prawirohardjo.

Departemen kesehatan RI. 2009. Buku Saku Pencegaham Kanker Leher Rahim dan Kanker Payudara. Jakarta: Depkes RI .

Kementrian Kesehatan Republik Indonesia. 2016. Data dan Informasi Profil Kesehatan Indonesia tahun 2016. Jakarta: Kemenkes RI.

Kementrian kesehatan RI. 2015. Panduan Program Nasional Gerakan Pencegahan dan Deteksi Dini Kanker Leher Rahim dan kanker Payudara. Jakarta: Kemenkes RI.

Kementrian Kesehatan. 2016. Profil Kesehatan Indonesia 2015. Jakarta: Kemenkes RI.

Kementrian Kesehatan. 2017. Profil Kesehatan Indonesia 2016. Jakarta: Kemenkes RI.

Kursani E, Dewi R. 2016. Faktor-faktor yang berhubungan dengan keikutsertaan wanita usia subur (WUS) dalam metode Inspeksi Visual Asam Asetat (IVA) Di Puskesmas Simpang Tiga Pekanbaru 2016. Jurnal Kesehatan Komunitas 4(1): 481-491.

Lestari T. 2015. Kumpulan Teori Untuk Kajian Pustaka Penelitian Kesehatan. Yogyakarta: Nuha Medika.

Mayasari E. 2017. Faktor-faktor yang mempengaruhi wanita usia subur yang tidak berminat dalam pelaksanaan tes Inspeksi Visual Asam Asetat (IVA) di wilayah kerja Puskesmas Rawat Inap Simpang Tiga Kota Pekanbaru tahun 2017. Prepotif 1(2): 93-98

Notoatmodjo S. 2014. Ilmu Perilaku Kesehatan. Jakarta: Rineka Cipta.

Notoatmodjo S. 2014. Metodologi penelitian kesehatan. Jakarta: Rineka Cipta.

Rasjidi I. 2008. Manual Prakanker Serviks. Jakarta: Sagung Seto.

Riset Kesehatan Dasar tahun 2013. 2013. Jakarta: Kementrian kesehatan RI.

Sari AN. 2017. Hubungan motivasi deteksi dini kanker serviks dengan tindakan Pap Smear pada wanita usia subur di Wilayah Gonilan. IJMS 4(2): 189-195.

Sartiwi W. 2017. Faktor-faktor yang berhubungan dengan pemeriksaan Inspeksi Visual Asam Asetat (IVA) terhadap deteksi kanker serviks pada WUS di wilayah kerja Puskesmas Paninggahan Kabupaten Solok. Jurnal Medika Saintika. 8(2): 33-44

Savitri A. 2015. Kupas Tuntas Kanker Payudara, Leher Rahim dan Rahim. Yogyakarta: Pustaka Baru Press. 